\title{
Suspicion for malpositioned ventriculoperitoneal shunt diagnosed with bedside ultrasound
}

\author{
Jay Biessel, Ross Keesling, Joe Betcher \\ Lake Michigan Emergency Specialists, Mercy Health Partners, Muskegon, MI, USA
}

\section{Case presentation}

A 27-year-old female presented to the emergency department with approximately eight hours of abdominal pain, nausea and vomiting, and abdominal wall swelling. She denied fevers or chills, or any recent history of abdominal trauma. She recently had a ventriculoperitoneal (VP) shunt placed six weeks ago for a cerebrospinal fluid leak with recurrent headaches associated with a Chiari 1 malformation. She was mildly tachycardic, with otherwise normal vital signs. Physical exam revealed a subcutaneous fluid collection measuring approximately $10 \mathrm{~cm} \times 10 \mathrm{~cm}$ with mild associated erythema in the right upper quadrant near her postoperative site.

Bedside ultrasound revealed a hypoechoic fluid collection surrounding a tubular foreign body found to be the patient's malpositioned VP shunt, which had externalized through her peritoneum and abdominal muscles (Figure 1). In the operating room, this shunt was externalized from the abdominal cavity and attached to a drainage bag, and subsequently completely removed several weeks later.

Interestingly enough, she had a VP shunt replaced several months later due to worsening headaches, only to have the same repeat complication of abdominal wall perforation. At that time,

Correspondence: Joe Betcher, Mercy Health Partners, 49444 Muskegon, MI, USA.

Tel.: 616.403.6908 - Fax: 231.727.5223.

E-mail: joebetcher@gmail.com

Key words: Ultrasound; Bedside; Education; Ventriculoperitoneal.

Contributions: all authors were present when obtaining the bedside ultrasound images in the clinical setting. JBe drafted the original manuscript, while RK provided multiple revisions to the manuscript. JBi obtained and edited images for appropriate quality. All authors reviewed and provided edits for the final copy of the manuscript.

Conflict of interest: the authors declare no potential conflict of interest.

Funding: none.

Received for publication: 23 March 2018.

Revision received: 19 June 2018.

Accepted for publication: 19 June 2018.

This work is licensed under a Creative Commons Attribution 4.0 License (by-nc 4.0).

CCopyright J. Biessel et al., 2018

Licensee PAGEPress, Italy

Emergency Care Journal 2018; 14:7433

doi:10.4081/ecj.2018.7433 the emergency physician used a CT scan for evaluation of her complication (Figure 2).

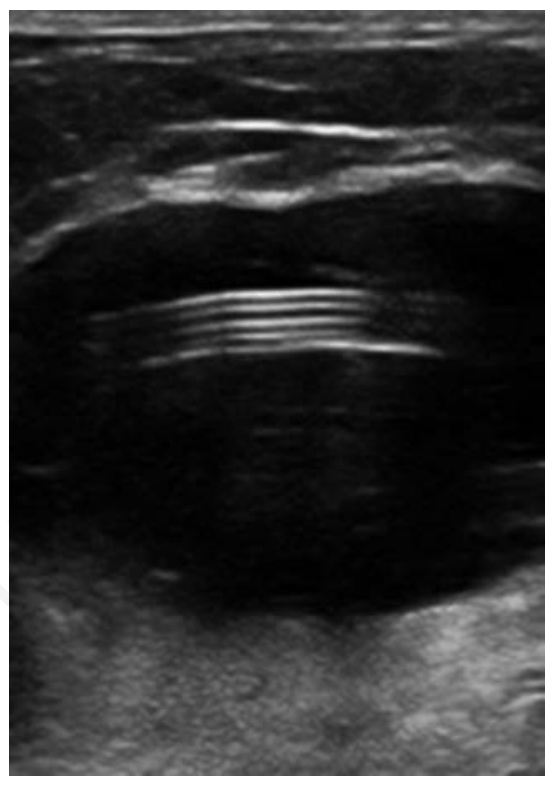

Figure 1. Bedside ultrasound revealing a hypoechoic fluid collection with a tubular foreign body.

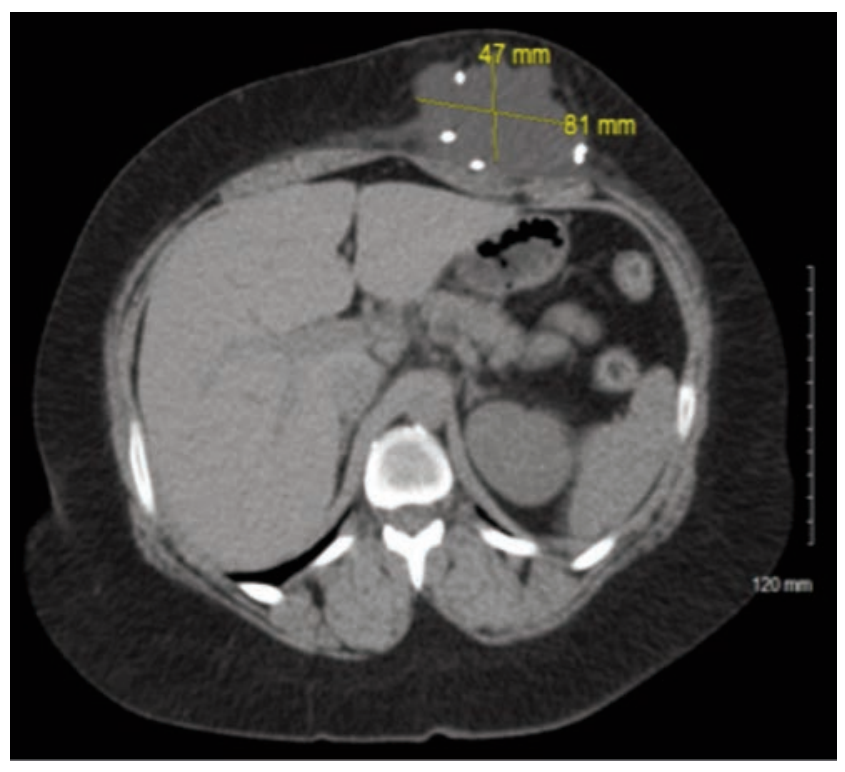

Figure 2. CT scan of the abdomen and pelvis with large fluid collection subcutaneously located in the LUQ, $4.7 \times 8.1 \mathrm{~mm}$ in size at the largest cross section. 


\section{Diagnosis}

This patient was diagnosed with a malpositioned VP shunt with abdominal wall fluid collection utilizing bedside ultrasound. There have been prior reports of extrusion of the peritoneal end of the VP shunt, including through the abdominal wall, umbilicus, and anus, all of which are rare complications. ${ }^{1}$ The pressure of the tip of the catheter on the local abdominal wall or viscera can lead to inflammation and erosion. ${ }^{2}$ Predisposing factors include infection, tube obstructions and multiple shunt revisions. ${ }^{3}$

\section{References}

1. Birbilis T, Theodoropoulou E, Matis G. Spontaneous externalization of peritoneal catheter through the abdominal wall in a patient with hydrocephalus: A case report. Cases J 2009; 16:6898.

2. Kanojia R, Sinha SK, Rawat J, et al. Unusual ventriculoperitoneal shunt extrusion: Experience with 5 cases and review of the literature. Pediatr Neurosurg 2008;44:49-51.

3. Mobley L, Doran S, Hellbusch L. Abdominal pseudocyst: predisposing factors and treatment algorithm. Pediatr Neurosurg 2005;41:77-83. 